$$
\text { CONF-960401--13 }
$$

\title{
LA-UR-9 $6-1239$
}

Title:

COADSORPTION OF NITRILES AND

CO ON CU-ZSM-5: AN IN SITU FTIR

SPECTROSCOPIC STUDY

Submitted to:

János Szanyi

Mark T. Paffett

CST-18

RECEIVED

APR 251996

OSTI

\section{Los Alamos}

NATIONAL LABORATORY

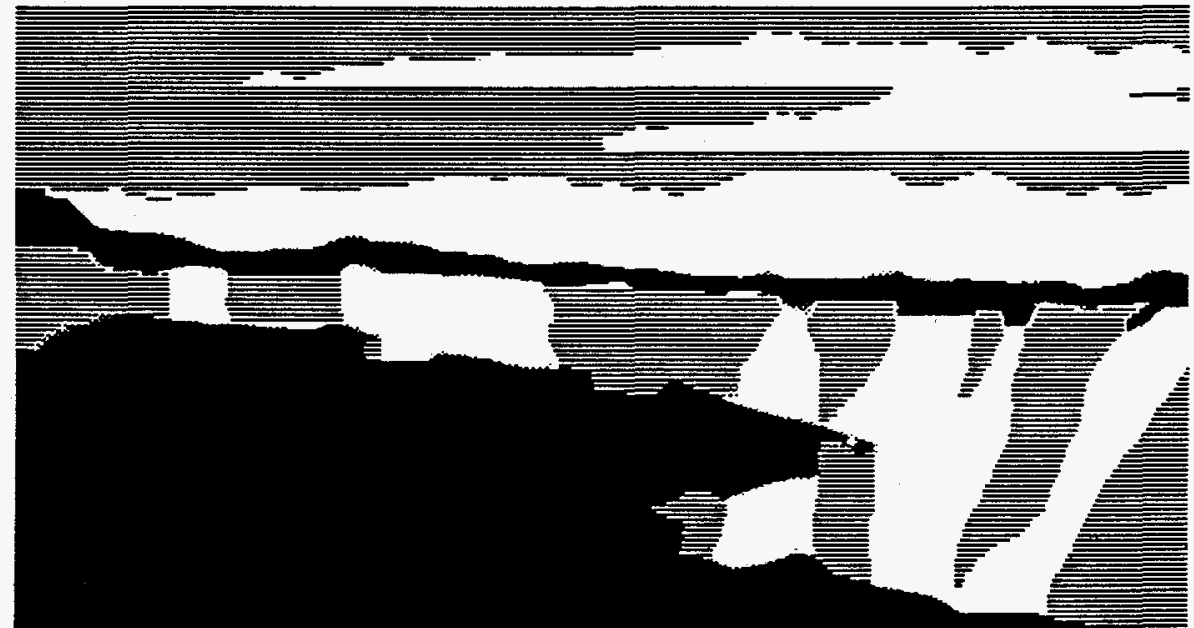

Los Alamos National Laboratory, an aflirmative actionequal opportunity employer, is operated by the University of Calltornia for the US Department of Energy under contract W-7405-ENG-36. By acceptance of this article, the publisher recognizes that the US Government relains a nonexclusive, royalty-free license to publish or reproduce the published form of this contribution, or to aliow others to do so, for US Government purposes. The Los royaliy-free license to publish or reproduce the published form of this contribution, or to aliow others to do so, for US Government purposes. The Los
Alamos National Laboratory requests that the publisher identity this article as work performed under the auspices of the US Depanment of Energy. 


\title{
COADSORPTION OF NITRILES AND CO ON Cu-ZSM-5: AN IN SITU FTIR SPECTROSCOPIC STUDY
}

\author{
J. SZANYI and M.T. PAFFETT \\ Los Alamos National Laboratory, Los Alamos, NM 87545
}

\section{ABSTRACT}

The coadsorption of acetonitrile ( $\mathrm{ACN}$ ) or deuterated acetonitrile $(\mathrm{dACN})$ with $\mathrm{CO}$ at $\mathrm{Cu}-\mathrm{ZSM}-5$ reveals several interesting features concerning the partial valency of $\mathrm{Cu}$. Specifically, $\mathrm{CO}$ binds at $\mathrm{Cu}^{+1}$ and $\mathrm{Cu}^{\circ}$ centers (in the absence of preadsorbed $\mathrm{ACN}$ ) and exhibits C-O stretching frequencies of $2157 \mathrm{~cm}^{-1}$ and $2112 \mathrm{~cm}^{-1}$, respectively. Carbon monoxide readily adsorbs at an $\mathrm{ACN}$ (or $\mathrm{dACN}$ ) saturated $\mathrm{Cu}-\mathrm{ZSM}-5$ and exhibits a $\mathrm{C}-\mathrm{O}$ stretch of $2122 \mathrm{~cm}^{-1}$, a value more consistent with a partially reduced $\mathrm{Cu}^{+1}$ center. Furthermore, the IR cross section for the $\mathrm{CN}$ stretch in a number of nitriles (ACN, dACN, and benzonitrile) coadsorbed with $\mathrm{CO}$ displays interesting effects attributed to rehybridization and changes in $\mathrm{CN}$ dipole moment.

\section{INTRODUCTION}

The catalytic opportunity that $\mathrm{Cu}-\mathrm{ZSM}-5$ has for potentially reducing $\mathrm{NO}_{\mathrm{x}}$ emission through reduction by hydrocarbons has prompted an enormous international examination of this material and the chemical properties it displays [1-6 and references contained therein]. Attendant with the study of this catalytic material there have been an ever expanding number of postulated mechanisms regarding how the $\mathrm{Cu}$ center in this material reacts with NO, $\mathrm{O}_{2}$ and hydrocarbon molecules [1-6]. Regardless of how the active metal center reacts with these gaseous species it is fairly certain that the $\mathrm{Cu}$ center itself undergoes substantial coordination geometry and partial valence changes. In this work we highlight a very ready demonstration of how coadsorbed gaseous species used in model studies of $\mathrm{NO}_{\mathrm{x}}$ reduction indirectly probe the local valence of $\mathrm{Cu}$ species in solid state exchanged ZSM-5 through changes in vibrational frequencies of coadsorbed species. The implication of how adsorption and coadsorbates alter valence changes at the active metal site has obvious practical implications in understanding how these materials operate mechanistically.

\section{EXPERIMENT}

All experiments were performed in a turbomolecularly pumped chamber derived from a $2.75^{\prime \prime}$ conflat six-way cross mounted vertically in the sample compartment of a Mattson Cygnus 100 FTIR spectrometer. Measurements were performed in the transmission mode at a typical frequency resolution of either 2 or $4 \mathrm{~cm}^{-1}$. Infrared specific components included an MCT detector, a $\mathrm{KBr}$ beam splitter, and $\mathrm{CaF}$ or $\mathrm{KBr}$ vacuum windows. Samples were powders pressed into tungsten wire mesh that was resistively heated using the methodology of Ref. 7. Sample temperatures $(95-1000 \mathrm{~K})$ were monitored using a type $\mathrm{K}$ thermocouple spot-welded to the center of the tungsten mesh. The sample meshes were supported on specially designed stainless steel mounts attached to a metal to ceramic feed-through mounted on a double wall $\left(1.00^{\prime \prime}\right.$ outside diameter) sample manipulator rod. The sample rod was mounted onto a linear motion translator that enabled it to be positioned above and at (in and out of the IR beam) the center portion of the sixway cross. Vacuum integrity was achieved by passing the rod through fixed spring-loaded teflon seals. A complete gas flow manifold with provisions for cleaning of gases and/or mass flow control of gaseous reactants are also attached to the experimental chamber. 
Acetonitrile, deuterated acetonitrile, and benzonitrile were all obtained from Aldrich Chemical and were degassed using several freeze-pump-thawed cycles prior to use. The $\mathrm{CO}$ used in these experiments was research purity from Matheson and it was stored in a glass bulb kept under liquid nitrogen to ensure the removal of metal-carbonyl (mainly Fe and $\mathrm{Ni}$ ) impurities present in research grade $\mathrm{CO}$ stored in metal cylinders. The zeolite sample was transferred into the IR beam, cooled and IR spectra were collected with gradually increasing sample temperature.

A Cu-ZSM-5 sample with essentially no free hydroxyls was prepared by solid-state ion exchange of $\mathrm{H}-\mathrm{ZSM}-5$ with $\mathrm{CuCl}$ in a slight variation of a method described in Ref. [8]. The solid-state ion exchange was carried out in a quartz tube reactor attached to a vacuum line. The parent $\mathrm{NH}_{4}-\mathrm{ZSM}-5$ sample was first slowly heated up to $850 \mathrm{~K}$ and annealed at this temperature for $6 \mathrm{hrs}$. This treatment resulted initially in the slow, systematic dehydration followed by the deammoniation of the ammonium form ZSM-5. The sample then was cooled back to room temperature and removed from the reactor. Cuprous chloride in an amount larger than that needed for the quantitative ion exchange of protons for $\mathrm{Cu}^{+}$ions was placed on the bottom of the quartz reactor. Then a thin layer of quartz wool was positioned on the top of the $\mathrm{CuCl}$ to prevent direct contact between $\mathrm{CuCl}$ and H-ZSM-5. The deammoniated H-ZSM-5 sample was then placed into the reactor and finally it was capped with a thick layer of quartz wool to protect the zeolite powder being sucked out of the vacuum line upon degassing and also to prevent to deposition of $\mathrm{CuCl}$ vapor in the vacuum line. The reactor prepared this way was first evacuated and then slowly heated up to about $400 \mathrm{~K}$ and kept at this temperature overnight to ensure the removal of adsorbed water from both the zeolite and the $\mathrm{CuCl}$. Then the reactor temperature was raised to $700 \mathrm{~K}$ to provide a sufficient $\mathrm{CuCl}$ vapor pressure for the solidstate ion exchange. The reactor was kept at this temperature for $6 \mathrm{hrs}$ and then it was heated up to $900 \mathrm{~K}$ to ensure the removal of all excess $\mathrm{CuCl}$ from the reaction zone.

Analytical characterization was accomplished using inductively coupled plasma mass spectroscopy and atomic emission spectroscopy. The elemental ratios for the $\mathrm{Cu}-$ ZSM-5 sample were: $\mathrm{Si} / \mathrm{Al}=27.9, \mathrm{Cu} / \mathrm{Al}=2.2$.

\section{RESULTS}

A) $\mathrm{CO} / \mathrm{Cu}-\mathrm{ZSM}-5$ and $\mathrm{ACN}$ (dACN)/Cu-ZSM-5: The adsorbates $\mathrm{CO}, \mathrm{ACN}$, and $\mathrm{dACN}$ were independently examined by IR as a function of sample temperature and partial pressure of the reactants. In this report we will focus on the fundamental vibration frequencies. For the sake of brevity; however, a more detailed description of all vibrational features for these adsorbates (and those also those observed for benzonitrile, trichloronitrile, and the $\mathrm{C} 1$ thru C3 nitroalkanes) will appear in another publication [9]. As reported previously [10] the C-O stretch was observed at $2157 \mathrm{~cm}^{-1}$ for adsorption on $\mathrm{Cu}^{+1}$ in ZSM-5. Catalyst pretreatment procedures such as oxidation and reduction cycles have been noted from in situ IR examination of adsorbed $\mathrm{CO}$ to produce several sites with the following respective $\mathrm{C}-\mathrm{O}$ stretching frequencies at near saturation coverage: $\mathrm{CO} / \mathrm{Cu}^{+2}$, $2195 \mathrm{~cm}^{-1}$; and $\mathrm{CO} / \mathrm{Cu}^{\circ}, 2212 \mathrm{~cm}^{-1}$ (gas phase $\mathrm{CO}, 2143 \mathrm{~cm}^{-1}$ ). In the present study the $\mathrm{Cu}-\mathrm{ZSM}-5$ sample was exposed to $\mathrm{ACN}$ (and $\mathrm{dACN}$ ) sufficient to populate one adsorbed molecule per $\mathrm{Cu}$ center. Although possible to force more $\mathrm{ACN}$ (dACN) onto $\mathrm{Cu}^{+1}$ sites, it was provident to work in a coverage regime where only one $A C N$ is located at each $\mathrm{Cu}^{+1}$ site. Excess $\mathrm{ACN}$ (or dACN) was pumped away prior to $\mathrm{CO}$ admission. Adsorbed $\mathrm{ACN}$ was observed to have a $C-N$ stretching frequency of 2298 and 2325 (the latter spectral signature arises from the Fermi resonance between a combination of $\delta \mathrm{s}(\mathrm{CH} 3)$ plus $\mathrm{v}(\mathrm{C}-\mathrm{C})$

and $\mathrm{C}-\mathrm{N}$ stretches). The gas phase acetonitrile $\mathrm{C}-\mathrm{N}$ stretch is seen at $2257 \mathrm{~cm}^{-1}$. The $\mathrm{C}-\mathrm{N}$ 
stretch for adsorbed dACN also observed at $2298 \mathrm{~cm}^{-1}$. In the following only $\mathrm{dACN}$ data will be shown.

B) $\mathrm{CO} / \mathrm{dACN}(\mathrm{ACN}) / \mathrm{Cu}-\mathrm{ZSM}-5$ coadsorption: A stack plot covering the C-O stretching region is shown for $\mathrm{CO}$ dosed onto a dACN saturated Cu-ZSM-5 sample in Fig. 1A. Note that the primary C-O stretch is seen at $2122 \mathrm{~cm}^{-1}$, approximately $35 \mathrm{~cm}^{-1}$ redshifted from the value observed for the same sample in the absence of $\mathrm{dACN}$ (or $\mathrm{ACN}$ ). The low intensity features observed at $2110 \mathrm{~cm}^{-1}$ and $2250 \mathrm{~cm}^{-1}$ arise from the symmetric and asymmetric C-D stretches in the deuterated methyl group of the preadsorbed dACN. Note that for the $\mathrm{C}-\mathrm{O}$ stretch no shift in the band position is observed as $\mathrm{CO}$ coverage is increased. However, the full width at half maximum (FWHM) is shown in Fig. 2 (after spectrally subtracting the C-D stretch component). Note that the FWHM is essentially constant until a relative coverage of 0.4 is reached at which point the width of the band linearly increases.

In Fig. 1B the C-N stretch region is shown for the dACN/Cu-ZSM-5 sample as the relative coverage of $\mathrm{CO}$ increases (the data series is the same set as shown in Fig.1A). Note that the C-N stretch is invariant in position until approximately 0.4 CO coverage is reached. Thereafter two features are very apparent in the spectra. First the $\mathrm{C}-\mathrm{N}$ band center redshifts $9 \mathrm{~cm}^{-1}$ to $2290 \mathrm{~cm}^{-1}$. Secondly, the absolute band C-N intensity increases approximately $100 \%$. Although not readily transparent, careful spectral subtraction over the C-D region clearly indicates that no new $\mathrm{dACN}$ is being adsorbed. This was further confirmed in examining the $\mathrm{C}-\mathrm{H}$ region of the CO/ACN/Cu-ZSM-5 system. An invariant integrated intensity of the $\mathrm{C}-\mathrm{H}$ stretch region indicates that no new $\mathrm{ACN}$ is adsorbing on the sample (data not shown for brevity).
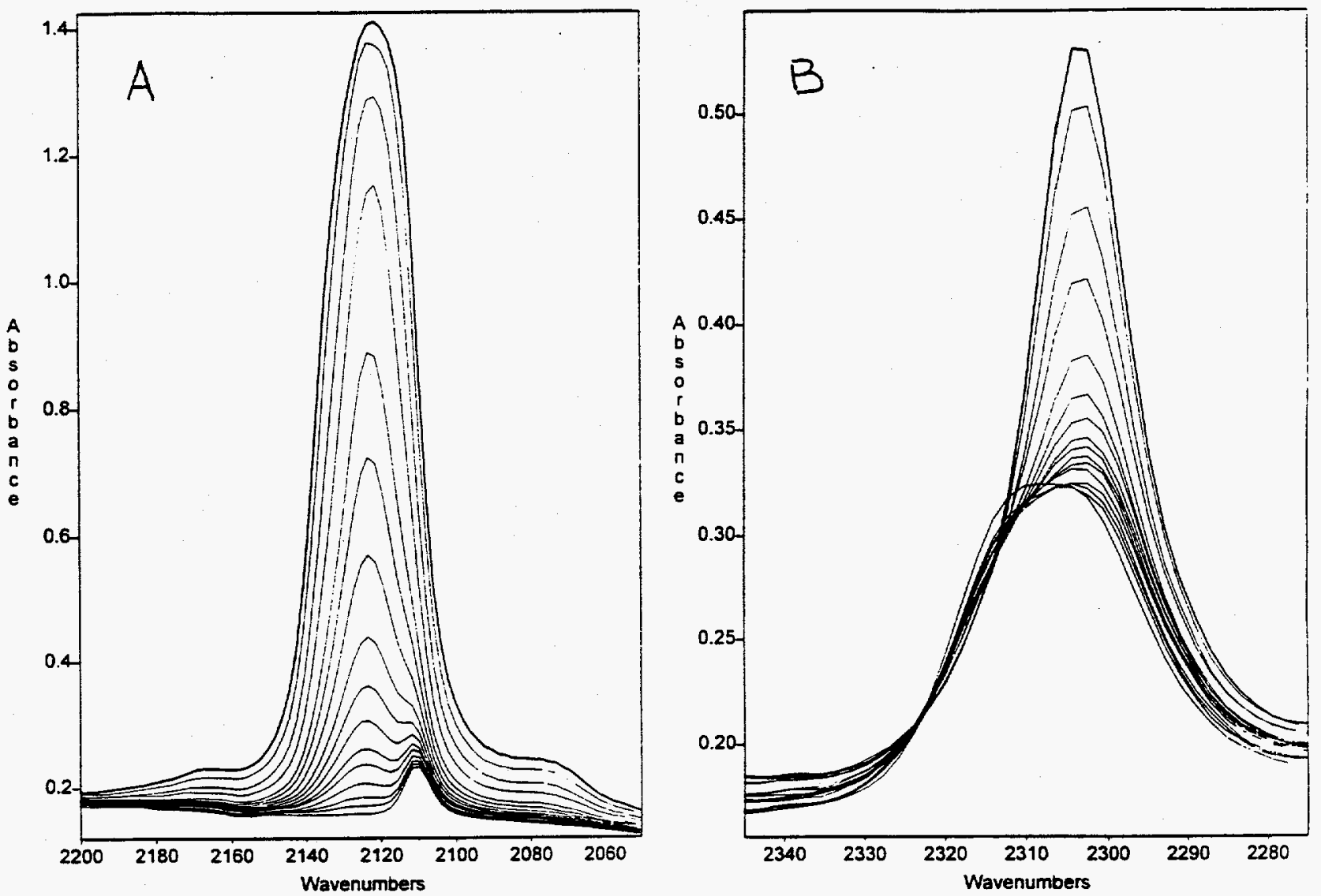

Fig. 1 A) C-O stretch region for various $\mathrm{CO}$ coverages at a dACN saturated Cu-ZSM-5; B) $\mathrm{C}-\mathrm{N}$ stretch region for $\mathrm{dACN}$ saturated $\mathrm{Cu}-\mathrm{ZSM}-5$ versus $\mathrm{CO}$ coverages of $\mathrm{A}$. 


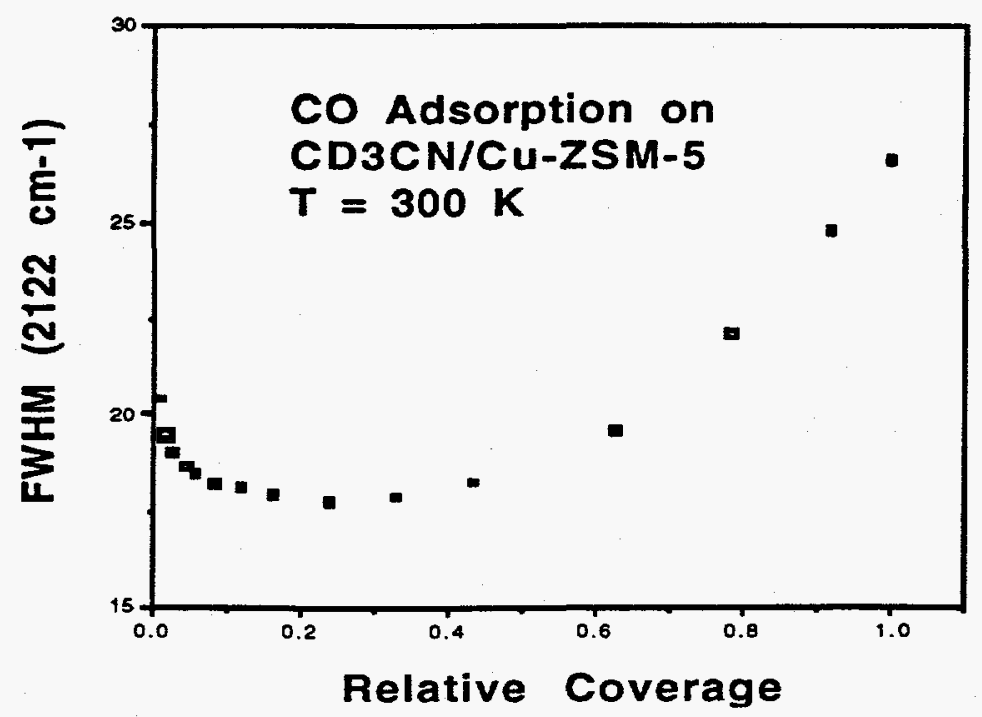

Fig.2 FWHM of $\mathrm{CO}$ stretch as a function of relative coverage at a dACN saturated $\mathrm{Cu}$-ZSM-5 sample.

\section{DISCUSSION AND POSTULATED MODEL}

Model: The interpretation of the interesting spectral shifts and intensity change in the $\mathrm{C}-\mathrm{N}$ stretch of the coadsorbed $\mathrm{dACN}$ (ACN) is suggested from the coordination complex model shown in Fig. 4. From analogy to the coordination chemistry observed in

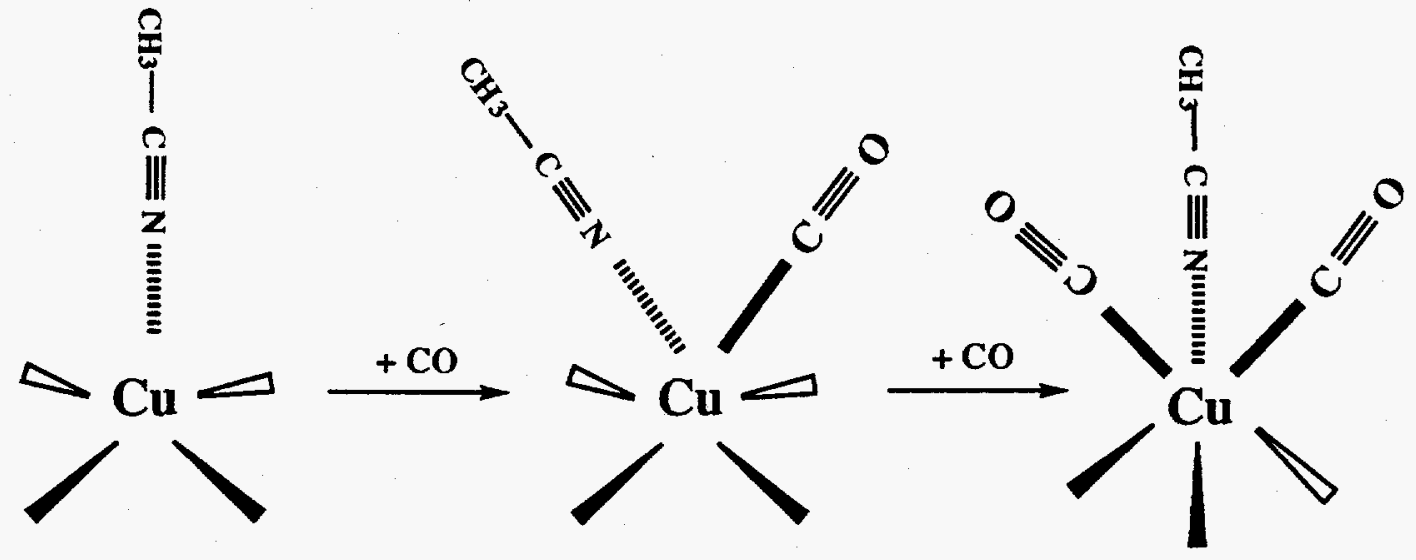

Fig. 4 Proposed Coordination Geometry in CO/ACN/Cu-ZSM-5 System (oxygen coordination to zeolite framework denoted by filled and unfilled triangles)

several inorganic $\mathrm{ACN}$ complexes $[11,12]$ the $\mathrm{ACN}$ molecule is drawn with a linear N-C-C bond extending from the $\mathrm{Cu}^{+1}$ center. As $\mathrm{CO}$ adsorbs at the $\mathrm{ACN} / \mathrm{Cu}^{+1}$ sites they are suggested to initially fill with one $\mathrm{ACN}$ and one $\mathrm{CO}$ at each center. Note that during this initial adsorption, the C-O stretching frequency is observed at $2122 \mathrm{~cm}^{-1}$, a value closer to a $\mathrm{Cu}^{\circ}$ center than $\mathrm{Cu}^{+1}$. With increased $\mathrm{CO}$ coverage two molecules eventually adsorb at each $\mathrm{ACN} / \mathrm{Cu}^{+1}$ site. The addition of the second $\mathrm{CO}$ weakens the $\mathrm{ACN}$ bonding to $\mathrm{Cu}^{+1}$ slightly such that the $\mathrm{CN}$ stretch is observed at a slightly lower energy and note (from Fig. 
1B) that the dipole moment of the adsorbed ACN must also increase leading to an enhanced IR absorption cross section. To accomplish this latter rehybridization the $\mathrm{Cu}^{+1}$ center is suggested to give up some degree of coordination to the oxygen centers in the zeolite. To test of the viability of the aforementioned model and in particular the last point, DFT [13] calculations of $\mathrm{CO}$ and ACN adsorption on Cu-ZSM-5 are currently in progress. These theoretical studies should provide interesting structural and themodynamic stability information with respect to the proposed intermediates suggested above. In describing a complex reaction scheme such as $\mathrm{NO}_{\mathrm{x}}$ reduction, it is perhaps an oversimplified notion that $\mathrm{Cu}$ centers retain a rigid valence state even for chemisorption.

\section{CONCLUSIONS}

Coadsorbed $\mathrm{CO}$ and acetonitrile (or deuterated $\mathrm{ACN}$ ) have been shown to be very sensitive to the electron density at the $\mathrm{Cu}^{+1}$ site when entrained in ZSM-5. The fundamental molecular stretching frequencies for $\mathrm{C}-\mathrm{O}$ and $\mathrm{C}-\mathrm{N}$ both shift in relation to the electron density changes at the $\mathrm{Cu}^{+1}$ site. Carbon monoxide coadsorbed at $\mathrm{Cu}^{+1}$ is seen at $2122 \mathrm{~cm}^{-1}$, a value considerably lower than that observed in the absence of ACN (2157 $\mathrm{cm}^{-1}$ ). The $\mathrm{C}-\mathrm{N}$ stretch for ACN coadsorbed with $\mathrm{CO}$ is also observed to shift to lower values but is suggested to do so only upon coordination of a second $\mathrm{CO}$ molecule on the $\mathrm{Cu}^{+1}$ site as shown in Figure 4. The often noted valence changes in the literature of $\mathrm{NO}_{\mathrm{x}}$ reduction indicate that subtle and interesting changes about the active metal site may play a very important role in its activity. In the present study, the coadsorption of common model compounds used in characterizing zeolite reactivity (e.g., $\mathrm{ACN}, \mathrm{CO}$ ) indicate that the adsorption process leads to a subtle valence redistribution at the adsorbate/metal center and potentially global site geometry changes within the zeolite host.

\section{REFERENCES}

1. M. Iwamoto, in "Zeolites and Related Microporous Materials: State of the Art 1994" (Eds. J. Weitkamp et al.) Studies in Surface Science and Catalysis Vol. 84 (1994) Elsevier Sci. B.V. pp. 1395.

2. M. Iwamoto, N. Mizuno, and H. Yahiro, in "New Frontiers in Catalysis", (Eds. L. Guczi et al.) Proceedings of the $10^{\text {th }}$ International Congress on Catalysis, 19-24 July, 1992, Budapest, Hungary (1993) Elsevier Sci. B.V. pp. 1287. 3. J. Valyon and W.K. Hall, in "New Frontiers in Catalysis" (Eds. L. Guczi et al.) Proceedings of the $10^{\text {th }}$ International Congress on Catalysis, 19-24 July, 1992, Budapest, Hungary (1993) Elsevier Sci. B.V. pp. 1339.

4. M. Shelef, C.N. Montreuil and H.W. Jen, Cat.Lett., 1994, 26, 277.

5. Smits, R., and Iwasawa, Y., Appl. Catal.B, 1995, 6, L201

6. Adelman, B.J., Beutel, T., Lei, G.-D., and Sachtler, W.M.H., J. Catal., 1996, 158, 327.

7. Ballinger, T.H., and Yates, J.T., Langmuir, 1991, 7, 3041.

8. G. Spoto, S. Bordiga, D. Scarano, and A. Zecchina, Catal. Lett., 1992, 13, 39.

9. Szanyi, J., and Paffett, M.T., unpublished results, 1996.

10. G. Spoto, S. Bordiga, A. Zecchina, G. Ricchiardi, and Matra, G., Appl. Catal. B, 1994, 3, 151.

11.Neuhaus, A., and Dehnicle, K., Zeitschrift fur Anorganische and Allgemeine Chemie, $1993,619,775$.

12. Schindler, S., Szalda, D., and Creutz, C., Inorg. Chem., 1992, 31, 2255 ,.

13. H. Brand and A. Redondo, LANL, 3/96, private communication. 


\section{DISCLAIMER}

This report was prepared as an account of work sponsored by an agency of the United States Government. Neither the United States Government nor any agency thereof, nor any of their employees, makes any warranty, express or implied, or assumes any legal liability or responsibility for the accuracy, completeness, or usefulness of any information, apparatus, product, or process disciosed, or represents that its use would not infringe privately owned rights. Reference herein to any specific commercial product, process, or service by trade name, trademark, manufacturer, or otherwise does not necessarily constitute or imply its endorsement, recommendation, or favoring by the United States Government or any agency thereof. The views and opinions of authors expressed herein do not necessarily state or reflect those of the United States Government or any agency thereof. 